\title{
Highly Regio- and Enantioselective Hydroformylation of Vinyl Esters Using Bidentate Phosphine,P-Chiral Phosphorodiamidite Ligands
}

\author{
Christian Schmitz, Katharina Holthusen, Walter Leitner,* and Giancarlo Franciò* \\ Institut für Technische und Makromolekulare Chemie, RWTH Aachen University, Worringerweg 2, 52074 Aachen, Germany
}

Supporting Information

ABSTRACT: Hybrid bidentate phosphine-phosphorodiamidite ligands based on a chiral Betti base backbone and diphenylphosphinoaniline derivatives have been prepared (BettiPhos). The ligands possess a stereogenic $\mathrm{P}$ atom at the phosphorodiamidite moiety, whose configuration can be largely controlled by the synthetic route and the choice of base and solvent. The new ligands were applied in the rhodium-catalyzed asymmetric hydroformylation (AHF) of vinyl esters and vinyl amides. Very high enantioselectivities of up to $97 \%$ ee accompanied by excellent regioselectivities (up to $\mathrm{b} / \mathrm{l}>$ 1000) were obtained using the BettiPhos ligand $\left(S_{\mathrm{C}}, S_{\mathrm{C}}, R_{\mathrm{P}}, S_{\mathrm{C}}\right)$-4b bearing an additional chiral group at the aniline nitrogen. The catalyst resting state $[\mathrm{RhH}-$

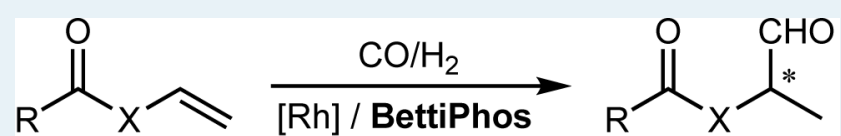

$X=\mathrm{O}, \mathrm{NH}, \mathrm{NMe}$ 13 examples ee up to $97 \%$

b/l up to $>1000$ $\left.(\mathrm{CO})_{2}\left\{\left(S_{\mathrm{C}}, S_{\mathrm{C}}, R_{\mathrm{P}}, S_{\mathrm{C}}\right)-\mathbf{4 b}\right\}\right]$ was investigated by high pressure-NMR studies, revealing an equatorial-apical coordination of the bidentate ligand where the two phosphorus donors rapidly exchange their positions through an intermediate with the ligand bound via the phosphine group only.

KEYWORDS: asymmetric catalysis, hybrid phosphorus ligands, hydroformylation, rhodium, P-stereogenic ligands

\section{INTRODUCTION}

Hydroformylation allows atom-efficient and direct formation of aldehydes from olefins and synthesis gas and has become a powerful synthetic tool for the preparation of these key organic intermediates. ${ }^{1}$ Nowadays, hydroformylation is the largest application of homogeneous catalysis on an industrial scale with a capacity of more than 10 million tons of oxo products per year and is almost exclusively targeted to the production of the linear isomer. ${ }^{2}$ In contrast, the regio- and stereoselective synthesis of chiral branched aldehydes is far less established, ${ }^{1}$ although these compounds are of special interest for the preparation of a variety of biologically active compounds and fine chemicals, such as chiral alcohols, acids, amines, diols, and amino alcohols. ${ }^{3,4}$

Among the reported ligands for asymmetric hydroformylation (AHF), only very few are capable of giving high chemo-, regio-, and enantioselectivity at the same time. For example, diphosphite ligands such as $(S, S)$-Chiraphite ${ }^{5}$ and $(S, S)$ Kelliphite $^{6}$ and diphosphine ligands such as $(S, S, S)$-Bisdiazaphos $^{7,4 \mathrm{c}, \mathrm{d}}$ and $(R, R)-\mathrm{Ph}-\mathrm{BPE}^{8}$ provided good to high enantioselectivities of $82-96 \%$ ee for styrene or vinyl acetate but only in a few cases have high regioselectivities (92-99\%) been obtained as well. ${ }^{9}$ Recently, the AHF of $Z$-enamides and various enol esters with a very high level of stereocontrol using $(S, S, S)$-Bisdiazaphos was demonstrated. ${ }^{4 c, d}$ Very recently, Vidal-Ferran reported that very high regio- and enantioselectivity can be achieved using bidentate phosphite ligands with a polyether backbone tunable through the addition of "regulating agents". 10

Since the seminal report of Takaya and Nozaki in 1993 on the phosphine-phosphite ligand Binaphos, ${ }^{11}$ hybrid bidentate ligands with two different phosphorus donors have been intensively investigated for AHF. ${ }^{1,3 f, 12}$ Very high enantioselectivities were achieved in the AHF of various substrate using a Binaphos derivative (up to $98 \%$ ee) ${ }^{11 \mathrm{~d} \text {,e }}$ or the related phosphine-phosphoramidite ligand Yanphos (up to $98 \%$ ee). ${ }^{13}$ Both ligands, however, do not excel in regioselectivity (8995\%). In contrast, the phospholane-phosphite Bobphos led to higher regioselectivities of 98-99\% but lower enantioselectivities of $83-92 \%$ ee. $^{14}$

Herein we report the synthesis of a new family of hybrid phosphine-phosphorodiamidite bidentate ligands bearing a stereogenic $\mathrm{P}$ atom (BettiPhos) and their application in the asymmetric hydroformylation of vinyl ester derivatives with exceptionally high regioselectivities (up to $>99.9 \%$ corresponding to $\mathrm{a} b / \mathrm{l}$ ratio $>1000)$ accompanied by very high enantioselectivities (ee up to 97\%). NMR investigations showed that in the resting state $\left[\mathrm{HRh}(\mathrm{CO})_{2}\left(\mathrm{P}-\mathrm{P}^{\prime}\right)\right]$ the phosphine and the phosphorodiamidite moieties occupy the equatorial and apical positions (major isomer $60 \%$ at $-70{ }^{\circ} \mathrm{C}$ ) or vice versa (minor isomer $40 \%$ at $-70{ }^{\circ} \mathrm{C}$ ). The two

Received: December 14, 2015

Revised: January 19, 2016

Published: January 22, 2016 
structures interconvert rapidly through an intermediate where the ligand is bound via the phosphine group only.

\section{RESULTS AND DISCUSSION}

Synthesis of Phosphine-Phosphorodiamidites. The ligand synthesis was accomplished from $(R, R)$-, $(R, S)$-, or $(S, S)$-Betti base $\mathbf{1}^{15,16}$ and 2-(diphenylphosphino)- $N$-phenylaniline $\mathbf{5} \mathbf{a}^{17}$ or $(S)$-2-(diphenylphosphino)- $N$-(1-phenylethyl)aniline $\mathbf{5 b},{ }^{17}$ using a previously explored synthetic methodology. ${ }^{16}$ The methods depicted in Scheme 1 via different routes, solvents, and bases provide good control of the configuration of the newly generated P-stereogenic center at the phosphorodiamidite moiety.

\section{Scheme 1. Ligand Synthesis}

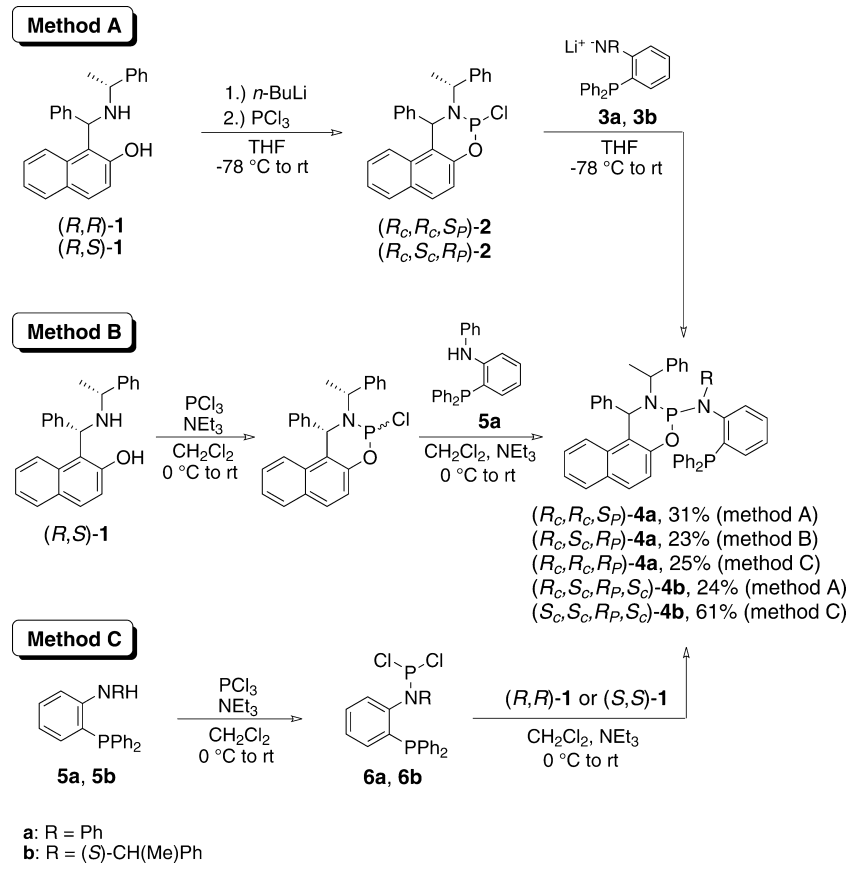

Method A involves first the treatment of Betti base $(R, R)-1$ or $(R, S)$-1 with $n$-butyllithium in THF followed by the addition of $\mathrm{PCl}_{3}$ and allows the stereoselective formation of phosphoramidochloridites $\left(R_{\mathrm{C}}, R_{\mathrm{C}}, S_{\mathrm{P}}\right)-2$ and $\left(R_{\mathrm{C}} S_{\mathrm{C}}, R_{\mathrm{P}}\right)-2$, respectively. The epimerically pure phosphoramidochloridites were then reacted with the lithiated 2-(diphenylphosphino)- $N$-phenylaniline 3a or (S)-2-(diphenylphosphino)-N-(1-phenylethyl)aniline $\mathbf{3} \mathbf{b}$ to give the desired phosphine-phosphorodiamidite ligands $\left(R_{\mathrm{C}}, R_{\mathrm{C}}, S_{\mathrm{P}}\right)-\mathbf{4 a}$ and $\left(R_{\mathrm{C}}, S_{\mathrm{C}}, R_{\mathrm{P}}, S_{\mathrm{C}}\right)-\mathbf{4 b}$ in $31 \%$ and $24 \%$ yields, respectively, after recrystallization from toluene/ethanol (Scheme 1).

Method B follows a similar reaction sequence using, however, triethylamine as base and $\mathrm{CH}_{2} \mathrm{Cl}_{2}$ as solvent. This method was applied for the preparation of ligand $\left(R_{\mathrm{C}}, R_{\mathrm{C}}, S_{\mathrm{P}}\right)-\mathbf{4 a}$ from $(R, S)-1$ and 2-(diphenylphosphino)- $N$-phenylaniline (5a). After recrystallization from toluene/ethanol, $\left(R_{\mathrm{C}}, R_{\mathrm{C}}, S_{\mathrm{P}}\right)-\mathbf{4 a}$ was obtained in $23 \%$ yield (Scheme 1).

Method C, which comprises the in situ formation of dichloraminophosphines $\mathbf{6 a}, \mathbf{b}$, was used for the synthesis of $\left(R_{\mathrm{C}}, R_{\mathrm{C}}, R_{\mathrm{P}}\right)-\mathbf{4 a}$ and $\left(S_{\mathrm{C}}, S_{\mathrm{C}}, R_{\mathrm{P}}, S_{\mathrm{C}}\right)-\mathbf{4 b}$, respectively. After purification by recrystallization from toluene/ethanol, the bidentate ligands were obtained in epimerically pure form and $25 \%$ and $61 \%$ yields, respectively (Scheme 1 ).
The absolute configuration of the phosphorodiamidite $\mathrm{P}$ atom of all BettiPhos ligands was assigned by comparison of the very characteristic chemical shifts in the ${ }^{1} \mathrm{H},{ }^{13} \mathrm{C}$, and ${ }^{31} \mathrm{P}$ NMR spectra and coupling constants $J^{1}{ }_{\mathrm{H}},{ }^{31} \mathrm{P}$ and $J^{13} \mathrm{C},{ }^{31} \mathrm{P}$ to the related monodentate phosphorodiamidite ligands based on the same Betti base backbone, where the $\mathrm{P}$ configuration was unambiguously determined via $\mathrm{X}$-ray crystal structure analysis. ${ }^{16}$

In the ${ }^{31} \mathrm{P}$ NMR, ligands $\left(R_{\mathrm{C}}, R_{\mathrm{C}}, S_{\mathrm{P}}\right)-\mathbf{4 a}$ and $\left(R_{\mathrm{C}}, S_{\mathrm{C}}, R_{\mathrm{P}}\right)-\mathbf{4 a}$ gave two sharp doublets for the phosphine and phosphoramidite moieties with through-space coupling constants $J_{\mathrm{P}, \mathrm{P}^{\prime}}$ of 48.5 and $42.6 \mathrm{~Hz}$, respectively. In contrast, broad signals were obtained for the phosphorodiamidite groups in $\left(R_{\mathrm{C}}, R_{\mathrm{C}}, R_{\mathrm{P}}\right)-\mathbf{4 a}$, $\left(S_{\mathrm{C}}, S_{\mathrm{C}}, R_{\mathrm{P}}, S_{\mathrm{C}}\right)-\mathbf{4 b}$, and $\left(R_{\mathrm{C}}, S_{\mathrm{C}}, R_{\mathrm{P}}, S_{\mathrm{C}}\right)-\mathbf{4 b}$ suggesting the presence of rotamers. Indeed, variable-temperature (VT) ${ }^{31} \mathrm{P}$ NMR showed for $\left(S_{\mathrm{C}}, S_{\mathrm{C}}, R_{\mathrm{P}}, S_{\mathrm{C}}\right)$-4b (see Figure $\mathrm{S} 1$ in the Supporting Information) two distinct sets of doublets of doublets at -40 ${ }^{\circ} \mathrm{C}$ with a ratio of 94:6 (major, $\delta_{\mathrm{P}}-21.1 \mathrm{ppm}, 140.6 \mathrm{ppm}, J_{\mathrm{P}, \mathrm{P}^{\prime}}=$ $30.3 \mathrm{~Hz}$; minor, $\left.\delta_{\mathrm{P}}-19.4 \mathrm{ppm}, 130.7 \mathrm{ppm}, J_{\mathrm{P}, \mathrm{P}^{\prime}}=33.1 \mathrm{~Hz}\right)$. The conformers may originate from hindered rotation at the $\mathrm{C}-\mathrm{N}$ bonds of the 1-phenylethyl groups both characterized by broad signals in the ${ }^{1} \mathrm{H}$ NMR even at $-40{ }^{\circ} \mathrm{C}$ (see Figure $\mathrm{S} 2$ in the Supporting Information).

Rh-Catalyzed Asymmetric Hydroformylation. The BettiPhos ligands were applied in the asymmetric hydroformylation of vinyl acetate. The catalytic systems were prepared in situ by addition of the bidentate ligand to a solution of $\left[\mathrm{Rh}(\mathrm{CO})_{2}(\mathrm{acac})\right]$ in a $\mathrm{Rh}: \mathrm{L}$ ratio of $1: 4$, and the reaction was carried out under standard conditions $\left(p\left(\mathrm{CO} / \mathrm{H}_{2}\right)\right.$ 30 bar (ratio $1: 1$ ), $T=60{ }^{\circ} \mathrm{C}, t=14 \mathrm{~h}$ ). The results are summarized in Table 1 .

Table 1. Rh-Catalyzed Asymmetric Hydroformylation of Vinyl Acetate Using Phosphine-Phosphorodiamidites $4^{a}$

$\begin{gathered}\mathrm{CO} / \mathrm{H}_{2} \text { (30 bar) } \\ \mathrm{mol} \%\left[\mathrm{Rh}(\mathrm{CO})_{2} \text { acac }\right] \\ 0.4 \mathrm{~mol} \% \text { ligand }\end{gathered}$
toluene, $60^{\circ} \mathrm{C}, 14 \mathrm{~h}$

${ }^{a}$ Conditions: substrate, $2 \mathrm{mmol}$; sub/Rh/L, 1000/1/4; toluene, $1 \mathrm{~mL}$; $p\left(\mathrm{CO} / \mathrm{H}_{2}\right)=30$ bar $(1: 1) ; T=60{ }^{\circ} \mathrm{C}, t=14 \mathrm{~h} .{ }^{b}$ Determined by ${ }^{1} \mathrm{H}$ NMR. ${ }^{c}$ Determined by chiral GC.

All ligands afforded moderately active hydroformylation catalysts exhibiting excellent regioselectivities. The relative configuration of the stereogenic phosphorus has little impact on the catalyst performance, and low enantioselectivities in favor of the $S$-aldehyde were obtained with both $\left(R_{\mathrm{C}}, R_{\mathrm{C}}, R_{\mathrm{P}}\right)-\mathbf{4 a}$ and $\left(R_{\mathrm{C}}, R_{\mathrm{C}}, S_{\mathrm{P}}\right)$-4a (Table 1 , entries 1 and 2$)$. In contrast, the change of the stereochemistry of the Betti-base backbone in $\left(R_{\mathrm{C}}, S_{\mathrm{C}}, R_{\mathrm{P}}\right)-\mathbf{4 a}$ had a very significant effect and led to the preferential formation of the opposite enantiomer with a similar ee value (entry 3 vs entry 1 ). The enantioselectivity could be substantially increased using the ligands $\mathbf{4 b}$ bearing an additional chiral moiety at the aniline nitrogen. In the presence of $\left(R_{\mathrm{C}}, S_{\mathrm{C}}, R_{\mathrm{P}}, S_{\mathrm{C}}\right)-\mathbf{4 b}, \mathbf{b 3 . 4 \%}(R)$ ee and very high regioselectivity were achieved, albeit at low conversion (entry 4$)$. Finally, the 
Table 2. AHF of Vinyl Acetate Using $\left(S_{\mathrm{C}}, S_{\mathrm{C}}, R_{\mathrm{P}}, S_{\mathrm{C}}\right)-4 \mathrm{~b}^{a}$

$\begin{array}{ccc}\text { entry } & \text { Sub/Rh } & T \\ 1 & 1000 & 60 \\ 2 & 500 & 60 \\ 3 & 1000 & 80 \\ 4 & 500 & 4 \\ 5 & 1000 & 60 \\ 6 & 1000 & 60 \\ 7 & 1000 & 6 \\ 8 & 300 & 40 \\ 9 & 100 & 25 \\ 10^{d} & 4000 & 40\end{array}$

$\left({ }^{\circ} \mathrm{C}\right)$
60
60
80
45
60
60
60
40
25
40

$\begin{array}{cc}\mathrm{CO} / \mathrm{H}_{2} & \mathrm{~L} / \mathrm{R} \\ 1 & \\ 1 & \\ 1 & \\ 1 & \\ 0.2 & \\ 1 & \\ 1 & \\ 0.2 & \\ 0.2 & \\ 0.2 & \end{array}$

$\begin{array}{cr}\mathrm{L} / \mathrm{Rh} & \text { convers } \\ 4 & > \\ 4 & > \\ 4 & \\ 4 & \\ 4 & \\ 2 & \\ 10 & \\ 4 & \\ 4 & \\ 4 & \end{array}$

$\begin{array}{lr}\mathrm{n}^{b}(\%) & \mathrm{b} / \mathrm{l}^{c} \\ 57 & >1000 \\ 99 & >1000 \\ 99 & >1000 \\ 54 & 497 \\ 86 & >1000 \\ 67 & 76 \\ 29 & >1000 \\ 91 & 859 \\ 49 & 257 \\ 22 & 49\end{array}$

$\begin{array}{rc}\mathrm{b} / \mathrm{l}^{c} & \mathrm{ee}^{c}(\%) \\ >1000 & 93.8 \\ >1000 & 94.0 \\ >1000 & 66.6 \\ 497 & 95.1 \\ >1000 & 94.2 \\ 76 & 64.4 \\ >1000 & 94.2 \\ 859 & 95.7 \\ 257 & 96.7 \\ 495 & 94.7\end{array}$

${ }^{a}$ Conditions unless specified otherwise: substrate, $2 \mathrm{mmol}$; toluene, $1 \mathrm{~mL} ; p\left(\mathrm{CO} / \mathrm{H}_{2}\right)=30 \mathrm{bar} ; t=14 \mathrm{~h} .{ }^{b}$ Determined by ${ }^{1} \mathrm{H}$ NMR. ${ }^{c}$ Determined by chiral GC ( $R$ enantiomer always preferentially formed). ${ }^{d}$ Reaction performed in $0.75 \mathrm{~mL}$ of substrate; $p=40$ bar.

diastereomer $\left(S_{\mathrm{C}}, S_{\mathrm{C}}, R_{\mathrm{P}}, S_{\mathrm{C}}\right)-\mathbf{4 b}$ based on Betti base $(S, S)-\mathbf{1}$ provided higher conversion (57\%), a regioselectivity exceeding $99 \%$, and $93.8 \%$ ee (entry 5 ).

Next, the reaction conditions for the AHF of vinyl acetate using BettiPhos $\left(S_{\mathrm{C}}, S_{\mathrm{C}}, R_{\mathrm{P}}, S_{\mathrm{C}}\right)$-4b were optimized (see Table $S 1$ in the Supporting Information for full screening). For better comparison the regioselectivities will be expressed as $b / 1$ ratios. The most important results are summarized in Table 2 .

Increasing reaction temperature led to enhanced reaction rate and lower ee (Table 2, entry 3 ), whereas the regioselectivity remained excellent. An enantiomeric excess of 95.1\% was achieved when the reaction was performed at $45{ }^{\circ} \mathrm{C}$ with $b / 1=497$ (Table 2, entry 4). No significant effect of the variation of the overall pressure was observed (see Table S1 in the Supporting Information), whereas an increased partial pressure of hydrogen $\left(\mathrm{CO} / \mathrm{H}_{2}=1 / 5\right)$ accelerated the reaction according to the hydroformylation kinetic law (Table 2, entry 5 vs 1$)^{2 a}$ The variation of the ligand/Rh ratio strongly affected the outcome of the reaction. When only 2 equiv of ligand was used, ee and $b / 1$ values dropped dramatically at a slightly increased reaction rate (Table 2 , entry 6). The use of 10 equiv of ligand provided excellent regio- and enantioselectivity, albeit at the expense of activity (Table 2, entry 7 ). When the AHF was carried out at lower temperature, substrate/ $\mathrm{Rh}$ ratio, and CO partial pressure, the enantioselectivity could be further increased. For instance, $95.7 \%$ ee was obtained at $40{ }^{\circ} \mathrm{C}$ with $91 \%$ conversion and $b / 1=859$ (Table 2 , entry 8 ). This result represents the best compromise in terms of catalyst activity and regio- and enantioselectivity. Furthermore, the catalyst was also active at $25{ }^{\circ} \mathrm{C}$, providing $96.7 \%$ ee, albeit at slightly reduced regioselectivity $(b / 1=257)$ (Table 2 , entry 9). When the reaction was performed in neat substrate at $40{ }^{\circ} \mathrm{C}, 22 \%$ conversion was achieved within $14 \mathrm{~h}$ with $94.7 \%$ ee and $\mathrm{b} / \mathrm{l}=$ 495 (Table 2, entry 10). This corresponds to $\mathrm{TOF}_{\mathrm{av}}=63 \mathrm{~h}^{-1}$. Attempts to preform the catalyst and then conduct AHF led to a racemic product mixture, because irreversible catalyst decomposition occurs upon releasing syngas before introducing the substrate. ${ }^{18}$

A series of vinyl esters and vinyl amides were hydroformylated using BettiPhos $\left(S_{\mathrm{C}}, S_{\mathrm{C}}, R_{\mathrm{P}}, S_{\mathrm{C}}\right)-\mathbf{4 b}$ under the optimized conditions identified above. The results are summarized in Table 3. In the AHF of vinyl propionate ee values of up to $95.5 \%$ were obtained, although a somewhat reduced branched/linear ratio of 121 was found in comparison to the vinyl acetate (Table 3, entries 1 and 2). The use of vinyl pivalate as substrate resulted again in excellent regioselectivities with $\mathrm{b} / \mathrm{l}$ values up to 451 and $94.6 \%$ ee. Interestingly, the
Table 3. AHF of Vinylic Substrates using $\left(S_{\mathrm{C}}, S_{\mathrm{C}}, R_{\mathrm{P}}, S_{\mathrm{C}}\right)-4 \mathrm{~b}^{a}$

\begin{tabular}{|c|c|c|c|c|c|c|}
\hline $\mathrm{Nr}$ & Substrate & $\begin{array}{l}\text { Sub/ } \\
\text { Rh }\end{array}$ & $\begin{array}{l}\mathrm{T} \\
\left({ }^{\circ} \mathrm{C}\right)\end{array}$ & $\begin{array}{l}\text { conv. }^{b} \\
(\%)\end{array}$ & $b / l^{c}$ & $e e^{c}(\%)$ \\
\hline 1 & & 1000 & 60 & 62 & 73 & $94.0(+)$ \\
\hline 2 & & 300 & 40 & 97 & 121 & $95.5(+)$ \\
\hline 3 & & 1000 & 60 & $>99$ & 292 & $94.2(+)$ \\
\hline 4 & & 300 & 40 & 97 & 451 & $94.6(+)$ \\
\hline 5 & & 1000 & 60 & 81 & 56 & $92.3(+)$ \\
\hline 6 & & 300 & 40 & 86 & 100 & $94 \cdot 7(+)$ \\
\hline 7 & & 1000 & 60 & 89 & 271 & $91.0(+)$ \\
\hline 8 & & 300 & 40 & 60 & $>1000$ & $91.3(+)$ \\
\hline 9 & & 1000 & 60 & 56 & $>1000$ & $91.7(+)$ \\
\hline 10 & & 300 & 40 & 73 & $>1000$ & $92.1(+)$ \\
\hline 11 & & 1000 & 60 & 95 & 61 & $81.7(-)$ \\
\hline 12 & & 300 & 40 & 80 & 81 & $88.0(-)$ \\
\hline 13 & & 1000 & 60 & 57 & 333 & $94.5(+)$ \\
\hline 14 & & 300 & 40 & 68 & 477 & $95.1(+)$ \\
\hline 15 & & 1000 & 60 & 23 & 158 & $94.0(+)$ \\
\hline 16 & & 300 & 40 & 35 & 381 & $95.8(+)$ \\
\hline 17 & & 100 & 60 & 3 & $<0.1$ & n.d. \\
\hline 18 & & 100 & 80 & $>99$ & 0.1 & $5(-)$ \\
\hline 19 & & 1000 & 60 & 31 & 10 & $63(+)$ \\
\hline 20 & & 300 & 40 & 22 & 25 & $82(+)$ \\
\hline 21 & & 1000 & 60 & 22 & 5 & $51(+)$ \\
\hline 22 & & 300 & 40 & 7 & 6 & $83(+)$ \\
\hline
\end{tabular}

${ }^{a}$ Conditions: substrate, $2 \mathrm{mmol}$; $\mathrm{Rh} / \mathrm{L}, 1 / 4$; toluene, $1 \mathrm{~mL} ; p(\mathrm{CO} /$ $\left.\mathrm{H}_{2}\right)=30$ bar $(1 / 5) ; t=14 \mathrm{~h} .{ }^{b}$ Determined by ${ }^{1} \mathrm{H}$ NMR. ${ }^{c}$ Determined by chiral GC.

catalyst activity was not negatively affected by the increased steric bulk of the tert-butyl group in the substrate (Table 3, entries 3 and 4). A comparable enantiomeric excess of $94.7 \%$ was achieved using vinyl benzoate as substrate, albeit at reduced yet high regioselectivity $(b / 1=100)$ (Table 3 , entries 5 and 6). For vinyl 4-methoxybenzoate again excellent regioselectivity 
(b/l > 1000) was observed, leading practically to a single regioisomer, accompanied by a slightly reduced enantioselectivity of $91.3 \%$ ee (Table 3, entries 7 and 8). Comparable results were obtained for vinyl 4-fluorobenzoate with $73 \%$ conversion, $b / 1>1000$, and $92.1 \%$ ee (Table 3 , entry 10 ). The AHF of vinyl 2-naphthoate resulted in up to $88 \%$ ee and b/l $=$ 81 at $80 \%$ conversion (Table 3, entries 11 and 12). The longchain vinyl laurate underwent hydroformylation with up to 95.1\% ee and excellent regioselectivity $(\mathrm{b} / \mathrm{l}=477)$ (Table 3, entries 13 and 14). When vinyl methacrylate was used as substrate, the exclusive hydroformylation of the vinyl group was observed, whereas the conjugated double bond was untouched (>99\% chemoselectivity in ${ }^{1} \mathrm{H}$ NMR). Enantioselectivities of up to $95.8 \%$ ee and a b/l ratio of 381 were obtained in this transformation (Table 3, entries 15 and 16). In contrast to the smooth hydroformylation of vinyl esters under mild conditions, the AHF of allyl acetate required elevated temperatures and afforded the desired aldehyde in only a poor enantiomeric excess of 5\% (Table 3, entries 17 and 18).

Finally, vinylamides were hydroformylated with BettiPhos $\left(S_{\mathrm{C}}, S_{\mathrm{C}}, R_{\mathrm{p}}, S_{\mathrm{C}}\right)$-4b. Vinylacetamide and $N$-methyl vinylacetamide underwent hydroformylation with $82 \%$ and $83 \%$ ee, respectively (Table 3, entries 19-22). The conversions obtained were somewhat lower in comparison to the previously investigated vinyl ester substrates, and also the regioselectivities were significantly lower (b/1 $=25$ and 6 , respectively), but still represent one of the best reported examples so far. ${ }^{19}$

Investigations on Catalyst Resting State $\left[\mathrm{RhH}(\mathrm{CO})_{2}(\mathrm{P}\right.$ $\left.\mathbf{P}^{\prime}\right)$ ]. The coordination mode of the ligand in the catalytic resting state is believed to play an important role for stereocontrol in the AHF. ${ }^{3 \mathrm{~d}, \mathrm{f}}$ For instance, the high level of enantioselectivity obtained with Binaphos was correlated with the equatorial-apical coordination mode adopted by the ligand in the resting state $\left[\mathrm{HRh}(\mathrm{CO})_{2}\left(\mathrm{P}-\mathrm{P}^{\prime}\right)\right]^{11 \mathrm{~b}, \mathrm{~g}} \mathrm{~A}$ recent $\mathrm{NMR}$ study showed, however, that the major species with the phosphine at the equatorial position and the phosphite group in the apical position is in rapid equilibrium with the isomer with reverse coordination with a ratio of up to $3: 1$ in $\mathrm{CD}_{2} \mathrm{Cl}_{2}$ at $-90{ }^{\circ} \mathrm{C} .{ }^{11 \mathrm{k}}$

The coordination mode of the BettiPhos ligand in [HRh$\left.(\mathrm{CO})_{2}\left(\mathrm{P}-\mathrm{P}^{\prime}\right)\right]$ was investigated via high pressure $(\mathrm{HP}) \mathrm{NMR}$. In a HP NMR tube (sapphire tube with a non-magnetic titanium head), the complex $\left[\mathrm{Rh}\left\{\left(S_{\mathrm{C}}, S_{\mathrm{C}}, R_{\mathrm{P}}, S_{\mathrm{C}}\right)-\mathbf{4 b}\right\}\right.$ (acac) $]$ was generated in situ from $\left[\mathrm{Rh}(\mathrm{CO})_{2}(\mathrm{acac})\right]$ and the ligand. In the ${ }^{31} \mathrm{P}$ NMR, this precursor displays two sets of doublets of doublets $\left(\delta_{\mathrm{P}}=34.4 \mathrm{ppm}\right.$, dd, $J_{\mathrm{P}, \mathrm{Rh}}=187.9 \mathrm{~Hz}, J_{\mathrm{P}, \mathrm{P}^{\prime}}=86.6 \mathrm{~Hz}$; $\delta_{\mathrm{P}^{\prime}}=153.9 \mathrm{ppm}$, dd, $\left.J_{\mathrm{P}^{\prime}, R h}=264.7 \mathrm{~Hz}, J_{\mathrm{P}, \mathrm{P}^{\prime}}=86.6 \mathrm{~Hz}\right)$. The HP NMR tube was then pressurized with $\mathrm{CO} / \mathrm{H}_{2}$ (30 bar), leading to the quantitative formation of the catalyst resting state $\left[\mathrm{HRh}(\mathrm{CO})_{2}\left\{\left(S_{\mathrm{C}}, S_{\mathrm{C}}, R_{\mathrm{P}}, S_{\mathrm{C}}\right)-\mathbf{4 b}\right\}\right]$ with the following resonances in ${ }^{31} \mathrm{P}$ NMR: $\delta_{\mathrm{P}} 19.3 \mathrm{ppm}$, dd, $J_{\mathrm{P}, \mathrm{Rh}}=112.3 \mathrm{~Hz}, J_{\mathrm{P}, \mathrm{P}}=59.4 \mathrm{~Hz}$; $\delta_{\mathrm{P}} 167.1 \mathrm{ppm}, \mathrm{dd}, J_{\mathrm{P}, \mathrm{Rh}}=174.6 \mathrm{~Hz}, J_{\mathrm{P}, \mathrm{P}}=59.4 \mathrm{~Hz}$. A single hydride species was visible in the ${ }^{1} \mathrm{H}$ NMR at $-9.2 \mathrm{ppm}$ (ddd, ${ }^{1} J_{\mathrm{H}, \mathrm{Rh}}=12.0 \mathrm{~Hz},{ }^{2} J_{\mathrm{H}, \mathrm{P}}=66.7 \mathrm{~Hz},{ }^{2} J_{\mathrm{H}, \mathrm{P}}=87.0 \mathrm{~Hz}$; see Figure S3 in the Supporting Information). Selective decoupling of each inequivalent $\mathrm{P}$ nucleus allowed us to unequivocally associate the ${ }^{2} J_{\mathrm{H}, \mathrm{P}}$ coupling constants of 87.0 and $66.7 \mathrm{~Hz}$ to the phosphorodiamidite and diphenylphosphine groups, respectively (see Figure S4 in the Supporting Information). The chemical shifts of the phosphorus signals as well as the ${ }^{1} J_{\mathrm{H}, \mathrm{Rh}}$ and $J_{\mathrm{P}, \mathrm{Rh}}$ coupling constants are in the expected range for a trigonal-bipyramidal structure with equatorial-apical coordination of the ligand. The similar ${ }^{2} J_{\mathrm{H}, \mathrm{P}}$ values, however, are indicative of a weighted average of cis and a trans coupling and do not support the presence of a single isomer. ${ }^{20}$ This observation rather suggests the presence of an equilibrium of two stereoisomeric $\mathrm{Rh}$ complexes $\left[\mathrm{HRh}(\mathrm{CO})_{2}\left\{\left(S_{\mathrm{C}}, S_{\mathrm{C}}, R_{\mathrm{P}}, S_{\mathrm{C}}\right)\right.\right.$ 4b $\}$ ] (each with equatorial-apical coordination of the BettiPhos ligand) which is not resolved on the NMR time scale at room temperature, as already observed for Binaphos. ${ }^{11 \mathrm{k}}$

This hypothesis was verified by conducting VT HP NMR experiments. Indeed, when the temperature was decreased, the hydride signal in the ${ }^{1} \mathrm{H}$ NMR broadened and then sharpened again to give two resolved but still slightly broad doublets at $-70{ }^{\circ} \mathrm{C}\left(\delta_{\mathrm{H}}-9.0\right.$ and $\left.-9.1 \mathrm{ppm}\right)$ exhibiting coupling constants of ${ }^{2} J_{\mathrm{H}, \mathrm{P}}=121 \mathrm{~Hz}$ (phosphine group) and ${ }^{2} J_{\mathrm{H}, \mathrm{P}}=194 \mathrm{~Hz}$ (phosphorodiamidite group), respectively (see Figures S5 and S6 in the Supporting Information). Additionally, a new broad doublet signal $\left({ }^{2} J_{\mathrm{H}, \mathrm{P}}=118 \mathrm{~Hz}\right.$, phosphine group) appeared at $-7.9 \mathrm{ppm}$ at $\mathrm{T} \leq-50{ }^{\circ} \mathrm{C}$. ${ }^{21}$ The large coupling constants observed are characteristic for $\mathrm{H}, \mathrm{P}$-trans coupling, whereas the small $\mathrm{H}, \mathrm{P}$-cis and the $\mathrm{H}-\mathrm{Rh}$ couplings were not resolved. The ratio of the hydride signals accounts for $37 \%(-7.9 \mathrm{ppm}), 26 \%$ (-9.0 ppm), and 37\% (-9.1 ppm). The ${ }^{31} \mathrm{P}$ NMR spectra varied accordingly upon a decrease in temperature. Three distinct broad peaks for the phosphine at $\delta_{\mathrm{P}} 14.7,21.7$, and 29.2 ppm as well as for the phosphoramidite group at $\delta_{\mathrm{P}} 170.9$, 161.0, and $129.0 \mathrm{ppm}$ were visible at $-70{ }^{\circ} \mathrm{C}$ (see Figures S7S9 in the Supporting Information). When the sample was heated again, these signals disappeared and signals were observed at room temperature that were identical with those found before the sample was cooled.

These observations strongly support the presence in solution of the two stereoisomeric Rh species 7-ea and 7-ae (Scheme 2),

\section{Scheme 2. Equilibrium of Diastereomeric \\ $\left[\mathrm{HRh}(\mathrm{CO})_{2}\left\{\left(S_{\mathrm{C}}, S_{\mathrm{C}}, R_{\mathrm{P}}, S_{\mathrm{C}}\right)-4 \mathrm{~b}\right\}\right]$ with Equatorial-Apical $\kappa^{2}\left(\mathrm{P}, \mathrm{P}^{\prime}\right)$ Coordination in 7 and $\kappa^{1}\left(\mathrm{P}, \mathrm{P}^{\prime}\right)$ in 8}

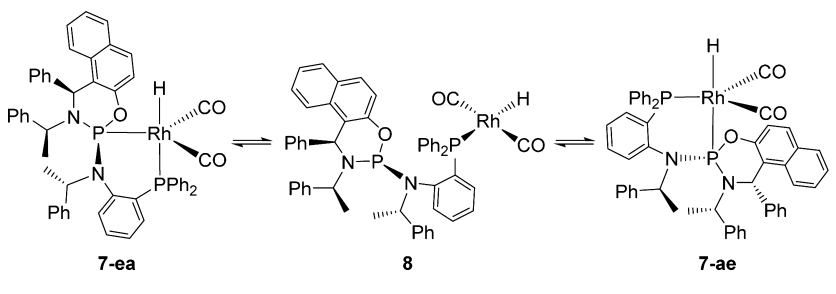

both exhibiting an equatorial-apical coordination of the bidentate ligand where the phosphine group of $\left(S_{\mathrm{C}}, S_{\mathrm{C}}, R_{\mathrm{p}}, S_{\mathrm{C}}\right)$ $4 \mathbf{b}$ occupies the axial position and the phosphorodiamidite the equatorial position (7-ea, $\delta_{\text {phosphine }}\left(-70^{\circ} \mathrm{C}, \mathrm{CD}_{2} \mathrm{Cl}_{2}\right) 21.7 \mathrm{ppm}$, $\left.\delta_{\text {phosphorodiamidite }} 161.0 \mathrm{ppm}\right)$ and vice versa $\left(7-\mathrm{ae}, \delta_{\text {phosphine }} 14.7\right.$ $\mathrm{ppm}, \delta_{\text {phosphorodiamidite }} 170.9 \mathrm{ppm}$ ) with an approximate ratio of 40:60. The additional NMR signals appearing at lower temperatures should arise from the square-planar species $\mathbf{8}$, where only the phosphine group at $\delta_{\mathrm{P}} 29.2 \mathrm{ppm}$ is coordinated to the $\mathrm{Rh}$ trans to the hydride and with a pendant phosphorodiamidite group characterized by the chemical shift $\delta_{\mathrm{P}} 129.0 \mathrm{ppm}$ upfield with respect to that observed in the free ligand $\left(\delta_{\mathrm{P}} 140.5 \mathrm{ppm}\right)$. The species 8 may serve as an intermediate in the isomerization of 7-ea and 7-ae.

At this stage it is not possible to distinguish which isomer(s) is/are responsible for the highly enantioselective turnovers in the AHF. However, following the analogy with Binaphos, ${ }^{11}$ the stereoisomer 7-ae with the phosphorodiamidite trans to the hydride would be the most plausible candidate. 


\section{CONCLUSIONS}

New hybrid phosphine-phosphorodiamidite bidentate BettiPhos ligands based on a chiral Betti-base backbone and diphenylphosphinoaniline derivatives have been prepared. The ligands possess a stereogenic $\mathrm{P}$ atom in the phosphorodiamidite moiety, whose configuration can be controlled to a large extent by the synthetic route. The BettiPhos ligands were applied in the rhodium-catalyzed asymmetric hydroformylation, combining very high enantioselectivities (up to 97\%) with exceptional regioselectivities (up to $b / l>1000$ ) for a variety of vinyl esters. Thus, the highly modular BettiPhos ligands define a new lead structure for the AHF of vinyl esters, providing synthetically useful selectivities.

In the resting state $\left[\mathrm{HRh}(\mathrm{CO})_{2}\left\{\left(S_{\mathrm{C}}, S_{\mathrm{C}}, R_{\mathrm{P}}, S_{\mathrm{C}}\right)-\mathbf{4 b}\right\}\right]$, the ligand exhibits an equatorial-apical coordination with the two $\mathrm{P}$ moieties rapidly exchanging their positions through a squareplanar intermediate where the ligand is bonded to the $\mathrm{Rh}$ via the phosphine donor only. These findings corroborate the assumption that an equatorial-apical coordination of the phosphorus ligand is a structural requirement for achieving highly enantioselective AHF, whereas a rigid environment is not and a fluxional behavior is tolerated.

\section{ASSOCIATED CONTENT}

\section{S Supporting Information}

The Supporting Information is available free of charge on the ACS Publications website at DOI: 10.1021/acscatal.5b02846.

Experimental details, NMR spectra, and GC traces (PDF)

\section{AUTHOR INFORMATION}

\section{Corresponding Authors}

*E-mail for W.L.: leitner@itmc.rwth-aachen.de.

*E-mail for G.F.: francio@itmc.rwth-aachen.de.

\section{Notes}

The authors declare no competing financial interest.

\section{ACKNOWLEDGMENTS}

Funding was provided by the European Union with the FP-7 integrated project SYNFLOW, http://synflow.eu. We thank Ines Bachmann-Remy for NMR measurements, Julia Wurlitzer and Hannelore Eschmann for GC measurements, and Sven Wiezorkowski for experimental assistance.

\section{REFERENCES}

(1) Franke, R.; Selent, D.; Börner, A. Chem. Rev. 2012, 112, 56755732

(2) (a) Claver, C.; van Leeuwen, P. W. N. M. In Rhodium Catalyzed Hydroformylation; Claver, C., van Leeuwen, P. W. N. M., Eds.; Kluwer Academic: Dordrecht, The Netherlands, 2000; Vol. 22. (b) Arpe, H.-J. Industrial Organic Chemistry, 5th ed.; Wiley-VCH: Weinheim, Germany, 2010.

(3) For reviews on AHF see: (a) Agbossou, F.; Carpentier, J. F.; Mortreux, A. Chem. Rev. 1995, 95, 2485-2506. (b) Claver, C.; Diéguez, M.; Pàmies, O.; Castillón, S. Top. Organomet. Chem. 2006, 18, 35-64. (c) Klosin, J.; Landis, C. R. Acc. Chem. Res. 2007, 40, 1251-1259. (d) Gual, A.; Godard, C.; Castillón, S.; Claver, C. Tetrahedron: Asymmetry 2010, 21, 1135-1146. (e) van Leeuwen, P. W. N. M. In Science of Synthesis: Stereoselective Synthesis 1; de Vries, J. G., Ed.; Thieme: Stuttgart, Germany, 2010; pp 409-476. (f) Chikkali, S. H.; van der Vlugt, J. I.; Reek, J. N. H. Coord. Chem. Rev. 2014, 262, 1-15. (g) Wong, G. W.; Landis, C. R. Aldrichim. Acta 2014, 47, 2938.
(4) For selected recent examples see: (a) Wang, X.; Buchwald, S. L. J. Org. Chem. 2013, 78, 3429-3433. (b) Xu, K.; Zheng, X.; Wang, Z.; Zhang, X. Chem. - Eur. J. 2014, 20, 4357-4362. (c) Abrams, M. L.; Foarta, F.; Landis, C. R. J. Am. Chem. Soc. 2014, 136, 14583-14588. (d) Risi, R. M.; Maza, A. M.; Burke, S. D. J. Org. Chem. 2015, 80, 204216. (e) Allmendinger, S.; Kinuta, H.; Breit, B. Adv. Synth. Catal. 2015, $357,41-45$.

(5) (a) Diéguez, M.; Pàmies, O.; Claver, C. Tetrahedron: Asymmetry 2004, 15, 2113-2122. (b) Babin, J. E.; Whiteker, G. T. WO 9303839, 1993. (c) Buisman, G. J. H.; Vos, E. J.; Kamer, P. C. J.; van Leeuwen, P. W. N. M. J. Chem. Soc., Dalton Trans. 1995, 409-417. (d) Buisman, G. J. H.; van der Veen, L. A.; Klootwijk, A.; de Lange, W. G. J.; Kamer, P. C. J.; van Leeuwen, P. W. N. M.; Vogt, D. Organometallics 1997, 16, 2929-1939. (e) Castellanos-Paez, A.; Castillón, S.; Claver, C.; van Leeuwen, P. W. N. M.; de Lange, W. G. J. Organometallics 1998, 17, $2543-2552$.

(6) (a) Cobley, C. J.; Klosin, J.; Qin, C.; Whiteker, G. T. Org. Lett. 2004, 6, 3277-3280. (b) Cobley, C. J.; Gardner, K.; Klosin, J.; Praquin, C.; Hill, C.; Whiteker, G. T.; Zanotti-Gerosa, A. J. Org. Chem. 2004, 69, 4031-4040.

(7) Clark, T. P.; Landis, C. R.; Freed, S. L.; Klosin, J.; Abboud, K. A. J. Am. Chem. Soc. 2005, 127, 5040-5042.

(8) (a) Axtell, A. T.; Cobley, C. J.; Klosin, J.; Whiteker, G. T.; Zanotti-Gerosa, A.; Abboud, K. A. Angew. Chem., Int. Ed. 2005, 44, 5834-5838. (b) Axtell, A. T.; Klosin, J.; Whiteker, G. T.; Cobley, C. J.; Fox, M. E.; Jackson, M.; Abboud, K. A. Organometallics 2009, 28, 2993-2999.

(9) van Leeuwen, P. W. N. M. In Science of Synthesis: Stereoselective Synthesis 1; de Vries, J. G., Ed.; Thieme: Stuttgart, Germany, 2010; pp 409-476.

(10) (a) Vidal-Ferran, A.; Mon, I.; Bauzá, A.; Frontera, A.; Rovira, L. Chem. - Eur. J. 2015, 21, 11417-11426. (b) Rovira, L.; Vaquero, M.; Vidal-Ferran, A. J. Org. Chem. 2015, 80, 10397-10403.

(11) (a) Sakai, N.; Mano, S.; Nozaki, K.; Takaya, H. J. Am. Chem. Soc. 1993, 115, 7033-7034. (b) Nozaki, K.; Sakai, N.; Nanno, T.; Higashijima, T.; Mano, S.; Horiuchi, T.; Takaya, H. J. Am. Chem. Soc. 1997, 119, 4413-4423. (c) Nozaki, K.; Takaya, H.; Hiyama, T. Top. Catal. 1997, 4, 175-185. (d) Nozaki, K.; Matsuo, T.; Shibahara, F.; Hiyama, T. Organometallics 2003, 22, 594-600. (e) Nozaki, K.; Matsuo, T.; Shibahara, F.; Hiyama, T. Adv. Synth. Catal. 2001, 343, 61-63. (f) Franciò, G.; Leitner, W. Chem. Commun. 1999, 16631664. (g) Franciò, G.; Wittmann, K.; Leitner, W. J. Organomet. Chem. 2001, 621, 130-142. (h) Horiuchi, T.; Ohta, T.; Shirakawa, E.; Nozaki, K.; Takaya, H. J. Org. Chem. 1997, 62, 4285-4292. (i) Horiuchi, T.; Shirakawa, E.; Nozaki, K.; Takaya, H. Organometallics 1997, 16, 2981-2986. (j) Shibahara, F.; Nozaki, K.; Hiyama, T. J. Am. Chem. Soc. 2003, 125, 8555-8560. (k) Castillo Molina, D. A.; Casey, C. P.; Müller, I.; Nozaki, K.; Jäkel, C. Organometallics 2010, 29, 33623367.

(12) For selected examples not included in ref $3 \mathrm{f}$ see: (a) Franciò, G.; Faraone, F.; Leitner, W. Angew. Chem., Int. Ed. 2000, 39, 1428-1430. (b) Hammerer, T.; Leitner, W.; Franciò, G. Chem CatChem 2015, 7, 1583-1592. (c) Fernández-Pérez, H.; Benet-Buchholz, J.; VidalFerran, A. Chem. - Eur. J. 2014, 20, 15375-15384. (d) Yu, Z.; Eno, M. S.; Annis, A. H.; Morken, J. P. Org. Lett. 2015, 17, 3264-3267.

(13) (a) Yan, Y. J.; Zhang, X. M. J. Am. Chem. Soc. 2006, 128, 71987202. (b) Zhang, X.; Cao, B.; Yan, Y.; Yu, S.; Ji, B.; Zhang, X. Chem. Eur. J. 2010, 16, 871-877.

(14) (a) Noonan, G. M.; Fuentes, J. A.; Cobley, C. J.; Clarke, M. L. Angew. Chem., Int. Ed. 2012, 51, 2477-2480. (b) Noonan, G. M.; Cobley, C. J.; Mahoney, T.; Clarke, M. L. Chem. Commun. 2014, 50, 1475-1477.

(15) Cimarelli, C.; Mazzanti, A.; Palmieri, G.; Volpini, E. J. Org. Chem. 2001, 66, 4759-4765.

(16) Schmitz, C.; Leitner, W.; Franciò, G. Eur. J. Org. Chem. 2015, $2015,6205-6230$.

(17) Eggenstein, M.; Thomas, A.; Theuerkauf, J.; Franciò, G.; Leitner, W. Adv. Synth. Catal. 2009, 351, 725-732. 
(18) HP NMR analysis indicates that the catalyst (resting state) decomposes at ambient pressure when the pressure is released. Upon repressurization with $\mathrm{CO} / \mathrm{H}_{2}$ a defined catalyst species is no longer formed. Unmodified $\mathrm{Rh}$ species might then be responsible for the catalytic activity without any asymmetric induction.

(19) McDonald, R. I.; Wong, G. W.; Neupane, R. P.; Stahl, S. S.; Landis, C. R. J. Am. Chem. Soc. 2010, 132, 14027-14029.

(20) In the case of an equatorial-axial coordination of the ligand a small ${ }^{2} J_{\mathrm{H}, \mathrm{P}}$ value in the range of $3-12 \mathrm{~Hz}$ would be expected for the cis coupling, whereas a ${ }^{2} J_{\mathrm{H}, \mathrm{P}}$ value in the range of $120-230 \mathrm{~Hz}$ would be expected for the trans coupling, depending on the electronic environment of the respective $\mathrm{P}$ atom. Here, the ${ }^{2} J_{\mathrm{H}, \mathrm{P}}$ values observed are between what is expected.

(21) Hydride signals in this region are commonly observed for $\mathrm{Rh}$ hydrido carbonyl complexes with ligands exhibiting a bis-equatorial coordination, as well as for complexes with monodentate ligands: see ref 5 .

\section{NOTE ADDED AFTER ASAP PUBLICATION}

After this paper was published ASAP February 11, 2016, the TOC and abstract graphics were corrected. The revised version was reposted February 17, 2016. 